\title{
\#VoteLGBT e o ciberativismo em prol da representação política no Brasil
}

\author{
\#VoteLGBT and cyberactivism to political representation in Brazil \\ \#VoteLGBT y el ciberactivismo en favor de la representación política \\ en Brasil
}

John Willian Lopes ${ }^{1, a}$

johnwillianlopes@gmail.com | http://orcid.org/00oo-0002-0676-9828

Maria do Socorro Furtado Veloso ${ }^{1, b}$

socorroveloso@uol.com.br | http://orcid.org/0000-0002-4515-0737

Juciano de Sousa Lacerda ${ }^{1, c}$

juciano.lacerda@gmail.com | http://orcid.org/000o-0002-0876-377X

\footnotetext{
${ }^{1}$ Universidade Federal do Rio Grande do Norte. Natal, RN, Brasil.

a Mestrado em Estudos da Mídia pela Universidade Federal do Rio Grande do Norte.

b Doutorado em Ciências da Comunicação pela Universidade de São Paulo.

c Doutorado em Ciências da Comunicação pela Universidade do Vale do Rio dos Sinos.
}

\section{Resumo}

Este artigo discute a emergência de iniciativas ciberativistas centradas na representação política LGBT, assim como a sua contribuição para a consolidação das demandas do movimento e para o aprofundamento da democracia. Com abordagem qualitativa e procedimento monográfico, objetiva-se compreender a atuação da campanha \#VoteLGBT, desenvolvida nas redes de comunicação digital distribuída nas eleições de 2014 e 2016. Delimitam-se, como corpus, as ferramentas sociais digitais utilizadas e os conteúdos das publicações realizadas no Facebook. Conclui-se que a iniciativa \#VoteLGBT produz uma tripla visibilização (das candidaturas para os eleitores; dos eleitores para os candidatos; das demandas e temáticas para os candidatos e eleitores); expõe desigualdades políticas veladas no próprio regime democrático; cumpre a função, ao usar ferramentas digitais, de aproximar as dimensões civil e política em uma mesma ambiência; busca, ao produzir conteúdo, sensibilizar e convocar os eleitores, demonstrando a legitimidade das pautas e a importância da participação e da representação política.

Palavras-chave: Movimento LGBT; Ciberativismo; Representação política; Democracia; Eleições; \#VoteLGBT.

\section{Abstract}

This article discusses the emergence of cyberactivist initiatives centered on LGBT political representation and its contribution to the consolidation of demands required by that movement and to deepen the democracy. With a qualitative approach and monographic procedure, the objective of this study is to understand the performance of the \#VoteLGBT campaign, developed in distributed digital communication 
networks before the Brazilian elections in 2014 and 2016. It was delimited as corpus the digital social tools used to those campaigns and the contents of the information posted in Facebook. We concluded that the \#VoteLGBT initiative produces a triple visibility (of candidates to voters, of voters to candidates, of demands and themes to candidates and voters); exposes veiled political inequalities in the democratic regime itself; in using digital tools, it fulfills the function of approaching the civil and political dimensions in the same environment; in producing content, it seeks to sensitize the voters to LGBT's issues and to choose their representant, demonstrating the legitimacy of those issues and the importance of political participation and representation.

Keywords: LGBT movement; Cyberactivism; Political representation; Democracy; Elections; \#VoteLGBT.

\section{Resumen}

Este artículo discute la emergencia de iniciativas ciberactivistas centradas en la representación política LGBT y su contribución para la consolidación de las demandas del movimiento y para la profundización de la democracia. Con un enfoque cualitativo y un procedimiento monográfico, el objetivo del estudio es comprender la actuación de la campaña \#VoteLGBT, desarrollada en redes de comunicación digital distribuida antes de las elecciones brasileñas de 2014 y 2016. Delimitamos como corpus las herramientas sociales digitales utilizadas en las campañas y los contenidos de las informaciones publicadas en Facebook. Concluimos que la iniciativa \#VoteLGBT produce una triple visibilidad (de candidatos para votantes, de votantes para candidatos, de demandas y temas para candidatos y votantes); expone desigualdades políticas veladas en el proprio régimen democrático; al emplear herramientas digitales, cumple la función de acercar las dimensiones civil y política en el mismo ambiente; al producir contenido, busca sensibilizar los votantes para las cuestiones LGBT y para elegir sus candidatos, demostrando la legitimidad de los temas y la importancia de la participación y representación política.

Palabras claves: Movimiento LGBT; Ciberactivismo; Representación política; Democracia; Elecciones; \#VoteLGBT.

Este artigo faz parte do dossiê $\mathbf{4 0}$ anos do movimento LGBT: visibilidades e representações.

Contribuição dos autores:

Concepção e desenho do estudo: John Willian Lopes, Maria do Socorro Furtado Veloso.

Aquisição, análise ou interpretação dos dados: John Willian Lopes.

Redação do manuscrito: John Willian Lopes, Maria do Socorro Furtado Veloso, Juciano de Sousa Lacerda.

Revisão crítica do conteúdo intelectual: John Willian Lopes, Maria do Socorro Furtado Veloso, Juciano de Sousa Lacerda.

Declaração de conflito de interesses: não há.

Fontes de financiamento: Programa de Demanda Social da Coordenação de Aperfeiçoamento de Pessoal de Nível Superior (CAPES).

Considerações éticas: o artigo apresenta os resultados da dissertação de mestrado "\#VoteLGBT: ciberativismo por representação política no Brasil", defendida no Programa de Pós-graduação em Estudos da Mídia da UFRN, em fevereiro de 2018.

Agradecimentos/Contribuições adicionais: não há.

Histórico do artigo: submetido: 31 jan. 2019 | aceito: 24 maio 2019 | publicado: 12 set. 2019.

Apresentação anterior: não houve.

Licença CC BY-NC atribuição não comercial. Com essa licença é permitido acessar, baixar (download), copiar, imprimir, compartilhar, reutilizar e distribuir os artigos, desde que para uso não comercial e com a citação da fonte, conferindo os devidos créditos de autoria e menção à Reciis. Nesses casos, nenhuma permissão é necessária por parte dos autores ou dos editores. 


\section{Introdução}

Os estudos no campo comunicacional, no Brasil, estão cada vez mais atentos à reflexão teórico-conceitual acerca do ciberativismo, dentro de um escopo geral de perceptível proliferação de trabalhos. Verifica-se, entretanto, que esses trabalhos ainda pouco repercutem investigações sobre iniciativas ciberativistas que envolvem as lutas políticas por direitos LGBT ${ }^{1}$. Essas lutas completarão meio século desde que irromperam no mundo, como uma força substantiva de questionamento social, político e cultural. Durante esse tempo, o processo de politização das identidades de gênero e orientações sexuais envolveu diferentes sujeitos e organizações que nem sempre foram concordantes em termos de perspectivas, atraindo múltiplas vozes discordantes em várias áreas da vida social ${ }^{2}$.

Nessa direção, o intuito deste artigo é evidenciar o modo como a emergência de iniciativas ciberativistas centradas na representação política LGBT contribui para a consolidação das demandas do movimento, ou seja, para o fortalecimento das pautas, do debate e para a criação e realização de políticas públicas e, por consequência, para o aprofundamento da democracia. Desse modo, a partir de uma abordagem qualitativa, analisa-se a atuação da campanha \#VoteLGBT, desenvolvida nas redes de comunicação digital distribuída ao longo das eleições nacionais brasileiras de 2014 e 2016.

Tal iniciativa surgiu no ano de 2014 como um empreendimento da sociedade civil, de caráter suprapartidário - portanto, independente de qualquer organização partidária -, com o objetivo principal de aumentar a representatividade pró-LGBT dentro dos partidos políticos, bem como no Poder Legislativo do país, com vistas ao desenvolvimento e à implementação de políticas públicas direcionadas à população LGBT. Organizada por ativistas sociais, a campanha define-se também como um coletivo autogerido e não institucionalizado, dedicado, além das campanhas durante os pleitos eleitorais, à contínua construção do debate acerca da temática da participação LGBT na política.

Entre os diferentes movimentos de grupos sociais minorizados, há uma demanda que é crescente: a participação política. Para Oliveira ${ }^{3}$, isso acontece por diferentes motivos: as novas necessidades criadas devido à inclusão social de novos segmentos sociais; a geração de demandas valorativas de combate a preconceitos; e a importância de a democracia institucional oportunizar, com relativa liberdade, a expressão e organização pública e coletiva - razões alinhadas com a possibilidade da disseminação das ideias e posicionamentos por meio das e nas redes de comunicação digital. Não obstante, há diferentes aspectos que limitam a participação de minorias sociais na política institucional, entre os quais as dificuldades para disporem de recursos materiais e financeiros e de tempo para dedicação política; a autoexclusão e a falta de anelo por ocupar posições de poder; e o não desenvolvimento de habilidades para ação na esfera política institucional4.

No contexto das democracias representativas ocidentais, participar politicamente significa também, conforme Santos 4 , lutar para ocupar as instituições representativas que são conduzidas por indivíduos de grupos sociais dominantes: geralmente homens, brancos, heterossexuais e de classe média e alta. De acordo com o autor, o domínio desses indivíduos nas esferas decisórias, definindo a agenda política e os termos do debate político, não contempla as demandas dos grupos minorizados nas políticas estatais e afasta a possibilidade de uma igualdade política substantiva.

A campanha \#VoteLGBT é considerada no espectro do ciberativismo na medida em que esse refere-se "às múltiplas práticas de sujeitos coletivos e individuais operadas em e nas redes de comunicação digital distribuída que objetivam a defesa de determinadas causas para promover mudanças na sociedade que favoreçam a vivência comum, recorrendo à circulação de ideias e de possibilidades técnicas (ferramentas) para engendrar formas de participação e intervenção"s.

Considerando esses aspectos, apontam-se aqui as condições que envolveram a constituição da campanha, a fim de identificar as estratégias comunicativas e ferramentas desenvolvidas. Nesse sentido, 
analisam-se tanto as ferramentas sociais digitais (site e plataforma), a partir da descrição das estruturas e funcionalidades, como a intenção da comunicação presente no conteúdo das publicações realizadas na página da iniciativa, num site de rede social, a partir da análise de conteúdo.

\section{Ciberativismo: conceitos e tipologias}

O ciberativismo surge na década de 1980 juntamente com a invenção do ciberespaço no período da história da "pré-web"'. Traçada por William Gibson, em 'Neuromancer", a ideia de ciberespaço refere-se ao território virtual de trocas, produção comum de linguagens e ações coletivas. A emergência do ciberativismo cria o ciberespaço com a formação das chamadas comunidades virtuais ${ }^{8}$, uma nova estrutura de organização social, que rompe com o ativismo social realizado até então no campo comunicacional` ${ }^{9}$ O ciberativismo, portanto, confunde-se com a própria expansão da internet ${ }^{10}$.

A formulação anterior que insere a iniciativa \#VoteLGBT no contexto do ciberativismo foi estruturada a partir de diferentes concepções conceituais que percebem esse fenômeno de diferentes maneiras, como movimentos sociais interconectados em rede ${ }^{11}$; como a utilização da internet por movimentos politicamente motivados ${ }^{12,13}$, com o objetivo de alcance de metas estabelecidas ou o embate com as injustiças que ocorrem na própria rede ${ }^{14}$; como estratégias de alteração da agenda pública a partir da propagação de significados pelos meios de comunicação e publicação eletrônica pessoal ${ }^{15}$; como qualquer ação realizada online por usuários com o objetivo de encaminhar os esforços coletivos para a mudança social ${ }^{16}$; como um conjunto de práticas realizadas nas redes cibernéticas a favor de causas políticas, socioambientais, sociotecnológicas e culturais $^{10}$; como biopolítica da rede ${ }^{9}$; como net-ativismo ${ }^{17}$ e biopolítica digital ${ }^{18}$.

As compreensões de ciberativismo são amplas, os esforços para conceituá-lo e as tentativas de categorização se diversificam, tal como os próprios termos utilizados por diferentes autores: 'ativismo digital', 'ativismo online', 'ativismo na internet', 'ativismo em rede', 'cibermilitância', 'netativismo', 'webativismo'. Muitos estudos utilizam indistintamente esses termos postos como conceitos, o que dificulta, em parte, a compreensão de rumos teóricos gerais. Aqui, optamos pelo termo ciberativismo e sob ele integramos as diferentes conceituações herdeiras de ordens teóricas múltiplas. Não há pretensão de canalizar ou remediar essas conceituações diversas para uma mesma noção; a ação tem o sentido de demonstrar entendimentos diferentes a partir de um objeto inicial comum de discussão.

Os diferentes entendimentos dos pesquisadores sobre o ciberativismo se espelham também nas categorizações diversificadas de tipos desse fenômeno, parte em decorrência dos estudos de diferentes formas de mobilização, do contexto em que as classificações foram elaboradas e das formulações teóricas balizadoras. Historicamente, há tipos de ativismo na e por meio da internet que são mais recorrentes enquanto objetos de investigação, como o hacktivismo, cuja história está associada ao desenvolvimento das redes digitais de comunicação, no âmbito da cultura hacker. Nesse tipo, é recorrente o uso não convencional do computador para melhorar algo útil, com aplicações políticas, sociais e culturais ${ }^{19}$.

Em uma compilação das tipologias ${ }^{20}$, podem-se observar orientações com tipos específicos de ciberativismo: a) 'portais' para olhar a ação direta política extraparlamentar na internet (ativismo computadorizado, desobediência civil eletrônica, hacking politizado); b) progressão de danos e perturbações causadas (ativismo, hacktivismo, ciberterrorismo); c) combinação dos tipos de ação social em relação à internet e de esfera social (internetworking - interconexão em rede -, fluxos de capital e informação, mídia alternativa, ciberativismo direto (hacktivismo), contestação e construção da internet, comunidades online); d) direção das iniciativas (conscientização/apoio, organização/mobilização, ação/reação - hacktivismo); e) forma estratégica das ações (campanha, swarming - enxameamento); f) tipos ideais examinados em pesquisas (brochure-ware - folheto digital -, facilitação online do ativismo offline, participação online, organização online); g) interatividade ou dimensão tecnológica e identidade ou forma discursiva (meta- 
ativismo, ativismo de empoderamento, ativismo de janela, ativismo de guerrilha); h) vertentes ideológicas dos ativistas da internet (defensores da privacidade; antimarcas; lacuna digital; software livre; copyleft e digital commons; hackers e hacktivistas; criadores de vírus).

Pode-se verificar que as noções e os tipos de ciberativismo propostos permitem englobar tanto práticas emancipadoras como aquelas consideradas o contrário, o que pode estar relacionado com certa dificuldade em se perceber as fronteiras dessas duas posturas e o que as torna ou não ciberativistas. Assim, neste artigo, adotou-se, conforme expresso na seção anterior, uma definição que visa "escantear as formas que tratam de

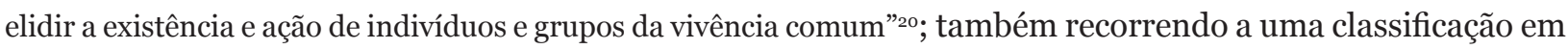
que a orientação se sustenta na direção das iniciativas.

Paralelamente ao aumento do interesse de pesquisadores pelo fenômeno do ciberativismo, verifica-se

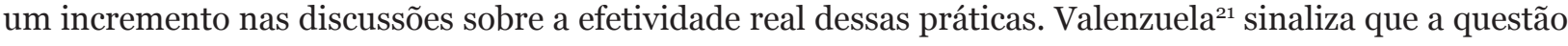
provocada acerca de saber se o uso das mídias sociais está ou não relacionado com a ação política tornou-se equivocada, considerando que vários estudos mostram uma profusão de evidências de que as pessoas que se envolvem em atividades cívicas e políticas são frequentes usuárias de mídias sociais digitais. Assim, torna-se mais importante saber como e sob que condições as novas mídias e plataformas digitais se relacionam com o ativismo cidadão e protesto político, isto é, como o uso delas se traduz em aumento da atividade política.

Essa relação entre redes de comunicação digital distribuída e participação e engajamento cívico-político é observada tanto por perspectivas otimistas como céticas. Por um lado, aponta-se que tal relação é estabelecida por meio da formação de redes de indignação, resultantes de demandas e deficiências sociais, políticas, econômicas, culturais e psicológicas, proporcionadas pela "consonância cognitiva" entre indivíduos emissores-receptores da mensagem e por um canal ou processo comunicativo eficaz ${ }^{22}$. Por outro lado, sinaliza-se que essas redes de indignação são inapropriadas para configurar o discurso e espaço públicos, devido ao caráter fluido e à volatilidade delas; além disso, a indignação digital não constitui um 'nós' estável que aponte para uma estrutura de cuidado conjunto da sociedade, logo, não engendra nenhum futuro ${ }^{23}$.

Colabora com essa assertiva, sobre a relatividade das práticas ciberativistas, a noção de filtro-bolha, apontada como responsável por examinar os gostos, as ações, relações e fazer extrapolações. Esse mecanismo cria um universo exclusivo de informações para as pessoas, o que altera o modo como cada uma delas se depara com ideias e informações nas redes digitais. No campo das relações sociais dessas novas dinâmicas, a partir do qual se pode associar e pensar o ciberativismo, as consequências surgem quando as pessoas começam a viver uma existência filtrada. A personalização excessiva "poderá nos impedir de entrar em contato com experiências e ideias estonteantes, destruidoras de preconceitos, que mudam o modo como pensamos sobre o mundo e sobre nós mesmos"24.

As discussões, confirmações e refutações empíricas e teóricas das consequências atribuídas ao ciberativismo sempre acompanharão os estudos das práticas conscientizadoras, mobilizadoras e organizadoras de ações e ideias em redes de comunicação digital distribuída. Cada vez que surge uma inovação tecnológica, ela se torna objeto do discurso da sociedade e de suas instituições, integrando uma trama cultural na qual poder e conhecimento se misturam, o que contribui para a sua ressignificação ${ }^{25}$. Nesse sentido, conforme alertam Tilly e Wood ${ }^{26}$, torna-se inevitável e substancial tratar dessas discussões, considerando que os movimentos sociais do início deste século têm incorporado os últimos avanços tecnológicos tanto a suas estruturas organizativas como a suas ações reivindicativas. É preciso, portanto, atentar para as mutações da tecnologia e seus usos sociais, políticos, culturais e econômicos, evitando, porém, o perigo do determinismo que tende a acompanhá-las. 


\section{Estratégia metodológica}

Apresentam-se aqui os movimentos que compõem a estratégia metodológica adotada no trabalho aqui apresentado, cujo método de procedimento é o estudo de $\mathrm{Caso}^{27}$, com abordagem qualitativa. Essencialmente, tal estratégia é formada por dois movimentos: investigação das ferramentas sociais digitais elaboradas e disponibilizadas para os pleitos eleitorais de 2014 e 2016, que correspondem ao site institucional e plataforma \#MeRepresenta; e investigação dos conteúdos publicados na página da iniciativa \#VoteLGBT no Facebook, definida como um tipo site de rede social ${ }^{28}$, durantes esses dois primeiros momentos de atuação.

Por meio da técnica de observação direta, para a análise das ferramentas sociais digitais, empregou-se, como ferramenta para coleta dos dados, o software gratuito HTTrack Website Copier, para realização do download na íntegra do site institucional da \#VoteLGBT e da plataforma \#MeRepresenta. Para a análise das publicações, empregou-se a extensão gratuita para navegadores FireShot, a fim de se copiar, através da captura de tela, as publicações da página no Facebook.

Em seguida, procedeu-se a análise descritiva e a discussão das estruturas e funcionalidades dos sites (ferramentas) desenvolvidas pela iniciativa. Para facilitar o entendimento acerca da distribuição dos conteúdos, optou-se por marcações através da delimitação de zonas com formas retangulares e numeração correspondente. Com o intuito de tornar a apresentação dos resultados mais objetiva, elaborou-se um quadro comparativo quanto com as características dessas ferramentas.

$\mathrm{Na}$ análise das publicações da página da campanha no Facebook, delimitaram-se dois períodos de coleta: 2014 (de 27 de agosto a 8 de outubro) e 2016 (de 19 de abril a 5 de outubro). Como técnica, optou-se pela análise de conteúdo (AC), para descrever de modo sistemático e objetivo o conteúdo das mensagens ${ }^{29}$. Assim, os resultados foram agrupados de modo a constituírem quatro tipologias de conteúdo.

Tendo em vista uma adequação da análise de conteúdo digital, foram consideradas, para a composição do corpus, as mensagens veiculadas na linha do tempo da página da campanha, enquadradas como 'publicações da página' pelos próprios mecanismos do Facebook. As notificações de atualizações das informações da página ou mesmo publicações de terceiros não foram contempladas.

Os formatos dos conteúdos possíveis nas publicações podem ser utilizados separadamente ou combinados. Assim, formatos diferentes em uma mesma publicação podem implicar diferentes enunciados, que eventualmente podem dificultar uma categorização mais precisa. Com isso, considerou-se que a diversidade de enunciados não resulta, obrigatoriamente, da presença de mais de um formato de conteúdo numa determinada publicação; logo, uma imagem pode conter mais de um enunciado. Por essa razão, considerou-se a publicação como um todo, em que se verifica a predominância de intenção da comunicação, a qual resulta da convergência de diferentes enunciados.

\section{Resultados e discussão}

\section{Ferramentas sociais digitais}

O site desenvolvido em 2014 foi pensado tanto para ser a ferramenta de auxílio aos eleitores como a página institucional da campanha. Assim, ambas as funções se mesclaram na estrutura da página, de modo que o usuário conseguisse compreender cada uma delas na interface. Ao entrar na página inicial do site, como mostra a Figura 1, o usuário já conseguia encontrar essa distinção, pois em uma parte havia caminhos que levavam aos conteúdos informativos da campanha e, na outra, caminhos que levavam aos das candidaturas.

Considerando as características observadas, é possível apontar que o site cumpriu uma função básica de curadoria, ou seja, concebia uma organização de candidaturas baseada em propostas pró-direitos de pessoas LGBT declaradas, que eram conferidas e chanceladas como aptas para serem disponibilizadas 
junto aos eleitores, cumprindo, assim, o objetivo inicial de visibilizá-las em conjunto com o debate sobre diversidade sexual e de gênero.

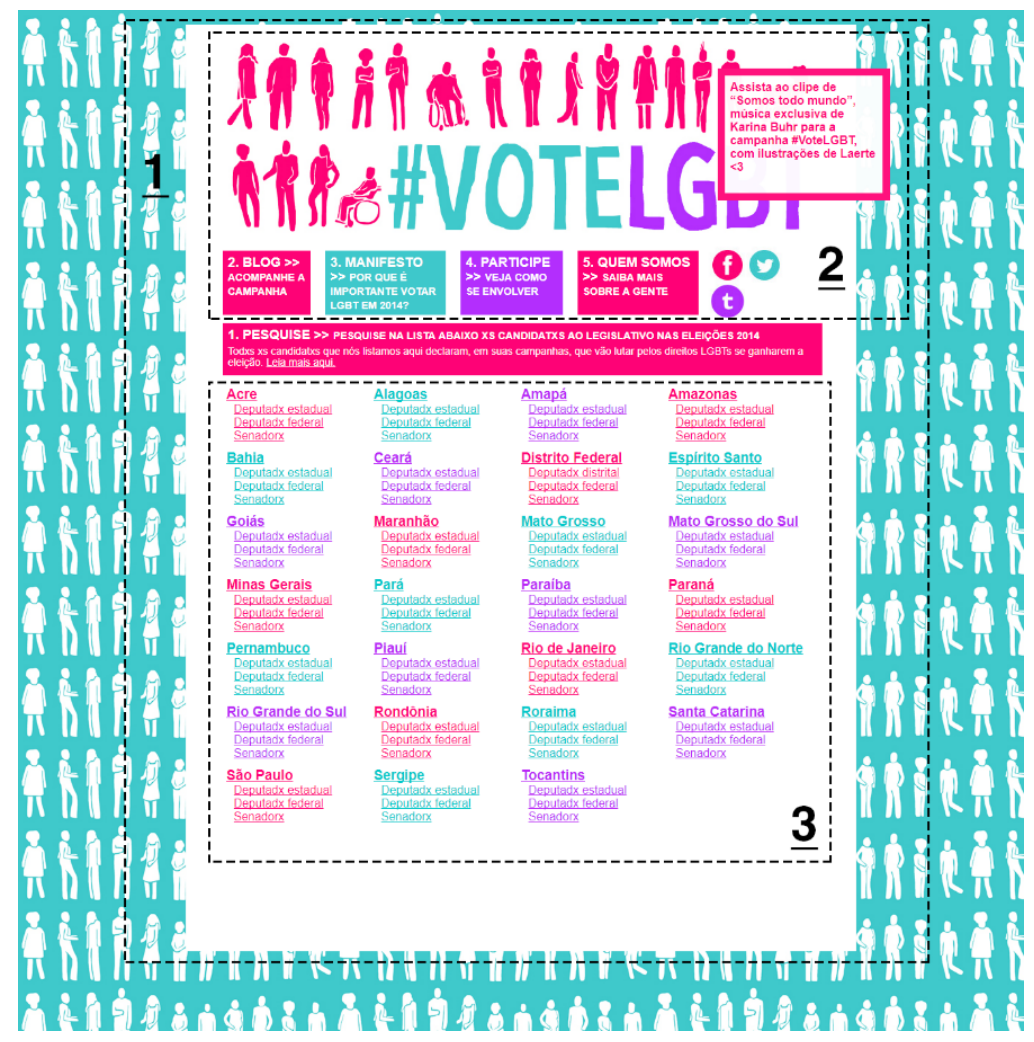

Figura 1 - Página inicial do site da campanha (2014)

Fonte: Lopes ${ }^{20}$.

Legenda: 1) Representa a zona com a prancheta principal de conteúdos do site; 2) Representa a zona do cabeçalho; 3) Representa a zona de conteúdos que variam de acordo com o menu acessado.

A busca e prospecção dos candidatos em 2014 eram realizadas pela organização da iniciativa, levando em conta as propostas apresentadas por eles em seus materiais de campanha ou, no caso daqueles eleitos anteriormente, que tiveram alguma atuação parlamentar pró-direitos LGBT, em suas atividades com esse objetivo. Os eleitores também podiam fazer indicações através do site, depois das quais era realizado um trabalho de checagem de cada nome, antes de visibilizá-lo. Assim, a partir do levantamento realizado na página, foram encontradas 269 candidaturas para o pleito de 2014 (29 para senador, 109 para deputado federal e 131 para deputado estadual) de todos os estados, mais o Distrito Federal, e de 19 partidos. Desses partidos, os que se consideram de esquerda no espectro político foram os que mais tiveram candidaturas alinhadas com as expectativas da iniciativa, ou seja, pró-direitos LGBT. São eles: Partido Socialismo e Liberdade - PSOL (93), Partido dos Trabalhadores - PT (67), Partido Socialista dos Trabalhadores Unificado - PSTU (32), Partido Comunista do Brasil - PCdoB (21) e Partido Socialista Brasileiro - PSB (19).

Considerando a distribuição por estado, os que tiveram mais candidaturas foram São Paulo (59), Rio de Janeiro (23), Distrito Federal (20), Minas Gerais (18), Rio Grande do Sul (17) e Pernambuco (16). Nota-se que esses estados estão também entre os dez maiores colégios eleitorais do país, de acordo com o Tribunal Superior Eleitoral (TSE). São Paulo, além de ter o maior número de eleitores, foi o local onde a \#VoteLGBT começou e onde reside a maioria dos organizadores da campanha. Tal fato, portanto, pode ter contribuído para que houvesse mais candidatos catalogados, justamente em razão da proximidade e familiaridade com o cenário político-estadual. Ao término das eleições, a campanha inseriu no site o desempenho dos candidatos (colocação, votos recebidos e se conseguiram ser eleitos ou não). A partir do levantamento e dos 
dados publicados no Facebook, verificou-se que, dos 269, foram eleitos 39, de nove partidos: 21 deputados federais, 17 deputados federais e um senador.

No ano de 2016, foi desenvolvido um novo site de apoio aos eleitores e candidatos, a plataforma \#MeRepresenta, o que significou uma mudança no modus operandi da atuação da iniciativa: mudaram-se as formas de cooptação, apresentação, busca e escolha dos candidatos; ampliaram-se as lutas reivindicadas e os atores que estão à sua frente. A plataforma surgiu a partir da cooperação entre diferentes coletivos e organizações ${ }^{\mathrm{i}}$, com o objetivo comum de promover o respeito aos direitos humanos, a partir das temáticas da diversidade sexual, identidade de gênero, igualdade racial e de gênero e direito à cidade. Desse modo, buscou diminuir a distância entre os cidadãos e a classe política, divulgando as posições dos candidatos acerca das pautas que constroem as temáticas apresentadas pela iniciativa e constituindo, assim, um tipo de banco de dados de acesso público.

A partir das características observadas, conclui-se que a plataforma se configura como uma ferramenta social digital cuja função básica foi de responsividade, ou seja, de coadunar as respostas dos cidadãos e da classe política, relacionando-as de modo a adequar os posicionamentos de ambos os perfis de usuários, eleitores e candidatos, no tocante a pautas específicas de direitos humanos, além de organizá-los e apresentá-los em uma interface. Essa adequação era responsável pela visibilização das opções de voto para os eleitores, que podiam decidir qual candidatura disponível ali os representava.

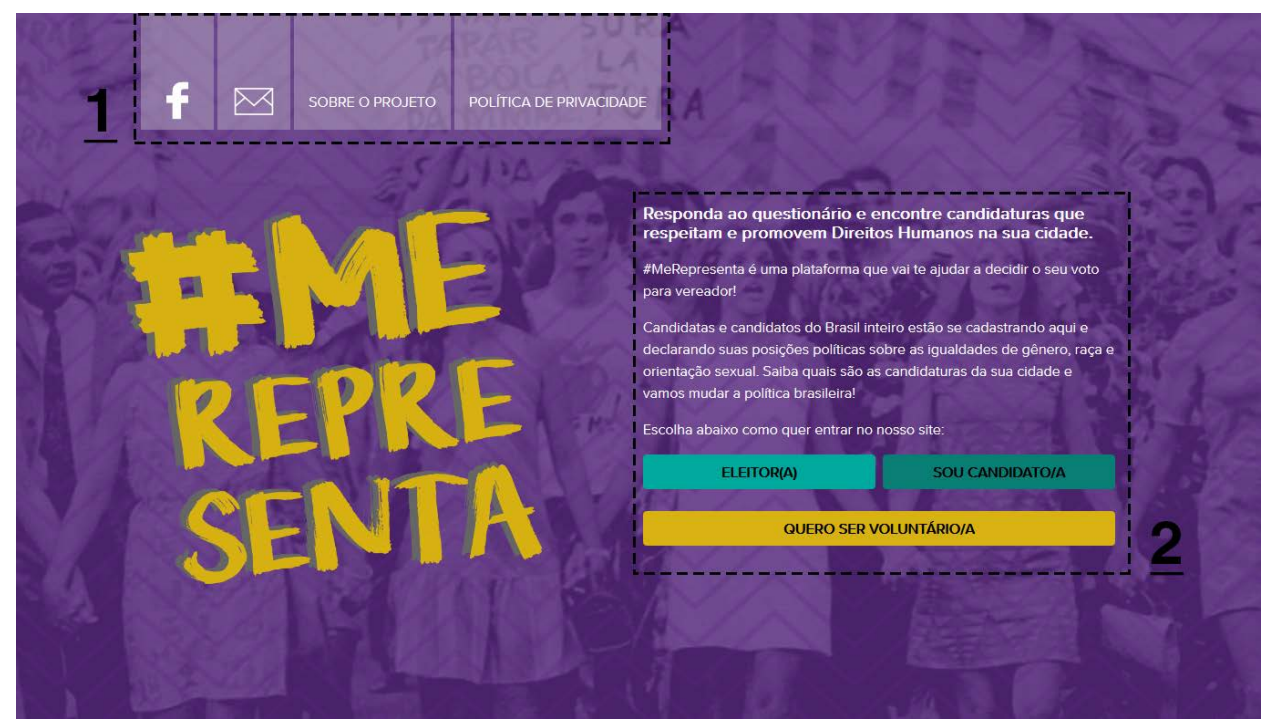

Figura 2 - Página inicial da plataforma \#MeRepresenta (2016)

Fonte: Lopes ${ }^{20}$.

Legenda: 1) Representa a zona com o menu do site; 2) Representa a zona que indica o tipo de acesso para cada perfil de usuário (eleitor, candidato e voluntariado).

Os candidatos que desejavam participar da plataforma \#MeRepresenta, cuja página inicial pode ser vista na Figura 2, deveriam realizar um cadastro por meio de uma conta no Facebook. Em seguida, precisavam fornecer dados pessoais e de campanha para a identificação. Havia, por fim, um processo de conferência dos dados, confrontando-os com aqueles disponibilizados pela Justiça Eleitoral, com o auxílio da ferramenta DivulgaCand. Os eleitores também deveriam realizar um cadastro na plataforma para poderem visualizar as candidaturas referentes nas suas cidades.

i A campanha \#VoteLGBT, a campanha \#AgoraÉQueSãoElas, a Rede Feminista de Juristas (DeFEMde), o grupo LGBT Brasil, a organização não governamental Centro Feminista de Estudos e Assessoria (CFEMEA) e a Rede Nossas Cidades (Meu Rio, Minha Sampa, Meu Recife e Minha Porto Alegre). 
Os candidatos tinham de responder a um questionário com 14 perguntas sobre direitos humanos, com alternativas de respostas 'sim' ou 'não'. A nota do candidato correspondia ao número de pautas declaradamente apoiadasii . O objetivo dessa delimitação de tipos de respostas era demarcar a posição dos candidatos quanto às pautas apresentadas (se favoráveis ou não), bem como facilitar a comparação entre eles e a escolha dos eleitores. As perguntas foram selecionadas a partir de pautas históricas dos movimentos sociais LGBTs, feministas, pela igualdade racial e de direito à cidadania.

Após o pleito, a organização da \#MeRepresenta disponibilizou os resultados para os eleitores na plataforma: 889 candidaturas para o cargo de vereador cadastradas, em 24 estados, 244 municípios e 35 partidos. Em 10 dias, a plataforma obteve mais de um milhão de visualizações e registrou cerca de 150 mil eleitores cadastrados. Além disso, 460 mil candidatos receberam convite por e-mail para participar e responder às perguntas relacionadas aos direitos humanos.

Novamente, os partidos alinhados com a esquerda e centro-esquerda tiveram mais candidatos registrados: PSOL (211), PT (167), Rede Sustentabilidade - REDE (51); PCdoB (51), Partido Verde - PV (39), Partido popular Socialista - PPS (31) e PSB (24). Na distribuição das candidaturas, embora a plataforma fosse aberta para qualquer candidato no Brasil, pode-se verificar que as cidades com números mais expressivos foram São Paulo (118), Campinas (62), Rio de Janeiro (58), Porto Alegre (53), Belo Horizonte (48) e Recife (43), considerando que nelas havia equipes de voluntários que buscaram as candidaturas e as pressionaram para participarem respondendo às perguntas.

O desempenho das candidaturas cadastradas na plataforma foi disponibilizado logo após o pleito: foram eleitos 57 vereadores em 37 municípios diferentes, distribuídos por 12 estados. Ao todo, 14 partidos tiveram algum eleito.

A campanha ciberativista \#VoteLGBT certamente não reuniu em seu site a totalidade das candidaturas próLGBT do Brasil; contudo, conseguiu mostrar que elas existem, que estão, em alguma medida, capilarizadas por diferentes partidos e estados e que puderam ser alcançadas com facilidade pelos eleitores. Por pouco mais de um mês, em 2014, foi possível visibilizar um número de candidatos que enfrentava o desconhecimento ou mesmo a rejeição da causa política e as demandas da população LGBT.

Esse curto período de campanha e um pequeno efetivo de pessoas na organização da iniciativa para explicar o número de candidatos cadastrados e visibilizados, uma vez que eles passavam por uma verificação das suas reais preocupações com a causa. Além disso, é possível considerar o fato de que muitos candidatos, por causa da falta de recursos financeiros ou humanos, não conseguiram elaborar ou divulgar com clareza as suas propostas - mesmo que houvesse intenções que fossem ao encontro das expectativas da iniciativa -, o que dificultou o trabalho de checagem e confirmação.

O site elaborado e disponibilizado pela campanha em 2014 oferecia recursos fundamentais para o conhecimento dos candidatos, sem exigir grande esforço por parte dos eleitores na navegação; mostrou-se objetivo, dentro das possibilidades, ao apresentar a listagem na primeira página. Ao mesmo tempo, para suprir a falta de mais informações sobre as intenções dos candidatos, a campanha realizou perguntas acerca das propostas e as disponibilizou juntamente com os dados dos candidatos.

Os partidos de esquerda no espectro político apresentaram o maior número de candidaturas pró-LGBT. Porém, nem sempre a chamada esquerda esteve alinhada com a pauta LGBT no Brasil e no mundo. Essa demora para compreender a importância das questões apresentadas deu-se por conta da visão de que um movimento multiclassista poderia prejudicar a classe operária trabalhadora ${ }^{30}$. Essa aproximação entre movimento LGBT e partidos políticos veio a ocorrer somente nos anos 1990, como a proposição de um projeto de lei - pela então deputada federal Marta Suplicy, do PT - contemplando a união civil entre pessoas do mesmo sexo.

ii O sistema de ranqueamento das candidaturas apresentadas ao eleitor considerou, além da nota atribuída a partir das respostas ao questionário, a avaliação dos partidos e das coligações com base na sua atuação na Câmara dos Deputados. 
Os partidos políticos com mais candidatos cadastrados no site são também aqueles que primeiramente implementaram setores ligados às pautas LGBT em suas estruturas partidárias, situação observada também nas siglas de centro ou direita. Essa multiplicação de setores, núcleos ou coletivos vinculados aos partidos pode ser relacionada com o processo de institucionalização das questões do movimento LGBT no país ${ }^{31}$.

A avaliação das candidaturas realizada pela plataforma \#MeRepresenta aproxima-se de uma compreensão de representação política nos termos da ideia de substância ${ }^{23}$, em que são consideradas as ações dos representantes frente aos interesses dos representados, de modo sensível (ou responsivo) a eles - nesse caso, a adesão dos candidatos às temáticas múltiplas materializadas nas 14 questões. Nesse sentido, verifica-se um deslizamento quanto à visão de representação, uma vez que em 2014 ela parecia se enquadrar dentro do que se chama de representação simbólica ${ }^{32}$, na qual o elemento de simbolização afetivo-emocional parece ser o 'ser LGBT' (além de representantes que defendiam direitos LGBT, era preciso que se identificassem como LGBT), ou o candidato representante precisa personificar as características desse grupo, aproximando-se da representação sociológica ${ }^{33}$.

Como se verifica, coletivos e organizações mobilizaram-se na empreitada da plataforma, o que certamente aumentou o alcance dos interessados em participar. Contudo, pode-se questionar também sobre a possibilidade de contendas ou mesmo de conflitos. Afinal, como garantir que eleitores e candidatos compreendam que aquelas pautas servem a um propósito maior - de respeito aos direitos humanos -, que estão em um mesmo nível de relevância e legitimidade e que, portanto, exigem deles certa coerência? A possibilidade oferecida de escolher ou não determinada pauta sugere que se deixou a critério dos usuários a definição sobre aquelas que compreendiam como mais oportunas para a decisão do voto ou para orientação de um possível mandato.

Quadro 1-Comparação das ferramentas sociais digitais de 2014 e 2016

\begin{tabular}{|c|c|}
\hline Site \#VoteLGBT (2014) & Plataforma \#MeRepresenta (2016) \\
\hline Característica curadora; & Característica responsiva; \\
\hline Cadastro de candidaturas realizado pela organização; & Cadastro de candidaturas realizado pelos interessados; \\
\hline $\begin{array}{l}\text { Critério de cadastro das candidaturas: posicionamento } \\
\text { público favorável às pautas LGBT; }\end{array}$ & $\begin{array}{l}\text { Critério de cadastro das candidaturas: aderência } \\
\text { às pautas de direitos humanos apresentadas na } \\
\text { plataforma; }\end{array}$ \\
\hline Consulta das candidaturas através de listagem; & Consulta das candidaturas através de ranqueamento; \\
\hline Sem possibilidade de cadastro dos eleitores; & Com possibilidade de cadastro do eleitor; \\
\hline Sem metodologia de avaliação de partidos e coligações; & $\begin{array}{l}\text { Com desenvolvimento de metodologia de avaliação de } \\
\text { partidos e coligações; }\end{array}$ \\
\hline Sem participação de outros coletivos e organizações; & Com participação de outros coletivos e organizações; \\
\hline $\begin{array}{l}\text { Oferecia recursos de convergência de formas } \\
\text { de conteúdos (texto, imagem e vídeo), de } \\
\text { hipertextualidade e interatividade; }\end{array}$ & $\begin{array}{l}\text { Oferecia recursos de convergência de formas } \\
\text { de conteúdos (texto, imagem e vídeo), de } \\
\text { hipertextualidade e interatividade. }\end{array}$ \\
\hline Acesso livre às candidaturas pelo eleitor usuário. & $\begin{array}{l}\text { Acesso às candidaturas pelo eleitor usuário } \\
\text { condicionado ao cadastro no Facebook; }\end{array}$ \\
\hline Layout não adaptado para multitelas. & Layout adaptado para multitelas. \\
\hline
\end{tabular}

Fonte: Lopes $^{19}$.

Assim, tanto o site da campanha \#VoteLGBT (2014) como a plataforma \#MeRepresenta (2016) são possibilidades técnicas ao alcance das iniciativas ciberativistas (ver o Quadro 1). São ferramentas criadas para fomentar maneiras de participar e intervir na política institucional brasileira, aproximando os cidadãos do debate - e dos debatedores já estabelecidos - e expondo o posicionamento dos políticos e dos seus partidos sobre temas importantes, como os direitos de pessoas LGBT, de mulheres, de negros e o direto à cidade. 


\section{Conteúdo das publicações no Facebook}

Através do agrupamento dos resultados, foram constituídas categorias (tipologias de conteúdo) utilizando a frequência como regra de enumeração, de modo que as 164 publicações documentadas (sendo 79 em 2014 e 85 em 2016) foram organizadas, como ilustra o Quadro 2, em quatro categorias temáticas: sensibilização do eleitor, repercussão na imprensa, chamada à ação e informativa. Cada uma foi dividida em outras subcategorias, de modo a proverem uma aproximação mais detalhada dos conteúdos das publicações, portanto das intenções presentes nelas.

Quadro 2 - Categorização do conteúdo das publicações da página \#VoteLGBT (2014 e 2016 juntos)

\begin{tabular}{|l|l|l|l|l|}
\hline Tipo & $\begin{array}{l}\text { Sensibilização do } \\
\text { eleitor }\end{array}$ & Repercussão na imprensa & Chamada à ação & Informativa \\
\hline $\begin{array}{l}\text { Número de } \\
\text { publicações }\end{array}$ & 69 & 23 & 44 & 28 \\
\hline
\end{tabular}

Fonte: Adaptado de Lopes, Nunes, Veloso5.

Quanto a essas categorias, verifica-se que:

I) Sensibilização do eleitor: publicações direcionadas aos eleitores com a intenção de torná-los sensíveis aos assuntos pertinentes abordados para, consequentemente, reagirem positivamente a eles e aos objetivos da iniciativa. Ao todo, 69 publicações constituíram essa categoria, 25 de 2014 e 44 de 2016 - nesse último ano, essa categoria correspondeu à maioria dos conteúdos publicados, enquanto, em 2014, foi a segunda com mais correspondentes.

Tal sensibilização ocorria através de um conteúdo diversificado, o que possibilitou sua subcategorização em cinco tipos: explicação do sistema político eleitoral, apelo à participação de personagens (depoimentos), apelo ao resgate histórico, apelo ao engajamento, apelo ao contexto imediato.

II) Repercussão na imprensa: publicações cuja intenção é registrar a inserção da campanha nos assuntos tratados pelos meios de comunicação, tradicionais ou não, de modo a demonstrar, em certa medida, que a iniciativa ganhava relevância midiática. Constituíram essa categoria 23 publicações - seis em 2014 e 17 em 2016.

Buscando compreender como ocorria tal inserção, chegou-se a duas subcategorias de tipos de conteúdos: notícia em jornal/portal e participação de organizadores em entrevistas.

III) Chamada à ação: publicações que intencionam propor aos eleitores a adesão a determinados posicionamentos voltados para a ação e resposta junto à iniciativa. Recorre a uma perspectiva convocatória da comunicação com vista a incitar os eleitores à participação imediata, ou seja, a expressarem determinadas atitudes que são interessantes para os objetivos da iniciativa. Essa categoria foi constituída por 44 publicações - 31 em 2014 e 13 em 2016.

Direcionada para os eleitores, essa categoria realiza-se de diferentes maneiras: por meio de participação no conteúdo da campanha, participação por demonstração de apoio, participação na organização (voluntariado), participação em debates propostos, instrução de utilização das ferramentas.

IV) Informativa: publicações que buscam anunciar aos eleitores as ações realizadas, ou seja, informá-los, em diferentes aspectos, acerca das atividades internas da campanha e relacionadas. Assim, 28 publicações constituíram essa categoria - 17 em 2014 e 11 em 2016.

O modo como os eleitores eram informados das atividades foi dividido em quatro subcategorias: anúncio de ação da campanha, anúncio de feitos/resultados, explicação de aspectos operacionais internos, anúncio de ação de terceiros. 
Comparativamente, observa-se que, no ano de 2016, priorizam-se os conteúdos cuja intenção da comunicação está voltada para a sensibilização dos eleitores e para a repercussão da campanha na imprensa, ao passo que, em 2014, destacam-se aqueles voltados para a chamada à ação por parte dos eleitores e para informá-los. Essa configuração se dá em razão de que o primeiro ano de atuação da \#VoteLGBT foi em 2014, portanto havia necessidade de esclarecer os eleitores sobre seus propósitos e funcionamentos, bem como se apelava para sua colaboração, principalmente no tocante ao conteúdo da campanha, levando em consideração que a busca das candidaturas naquele momento era realizada pela organização, a partir da conferência das propostas apresentadas.

Em 2016, houve um trabalho mais intenso de articulação com a imprensa, de veículos de comunicação a canais no YouTube. Isso contribuiu para que a iniciativa repercutisse na própria mídia, com jornalistas buscando novas pautas e encontrando novas plataformas coletivas empenhadas em discutir e fazer política de forma colaborativa. Contribuiu, também, para que os eleitores tomassem conhecimento da iniciativa e de como estava sendo proposta.

Ao longo da sua atuação nas redes de comunicação digital distribuída, em 2014 e 2016, a iniciativa \#VoteLGBT adotou, como principal estratégia comunicativa (intenção de comunicação), o emprego de recursos voltados para a sensibilização e convocação dos eleitores (chamada à ação), através de conteúdos cujos significados refletiam a dimensão e legitimidade das suas pautas e dos debates que as envolvem, ao mesmo tempo que demonstravam a importância do envolvimento, e de como fazê-lo, com os processos institucionais de participação - como as eleições - e seu reflexo no aumento substantivo da representação política LGBT no Brasil 5 .

\section{Conclusão}

Neste artigo, materializa-se uma pesquisa que se norteou pelo questionamento sobre como a emergência de iniciativas ciberativistas centradas na representação política LGBT contribui para a consolidação das demandas do movimento e também para o aprofundamento da democracia. Assim, buscou-se compreender a atuação da campanha \#VoteLGBT, uma iniciativa desenvolvida nas redes de comunicação digital distribuída. A investigação apontou as condições para a constituição da campanha, identificando e analisando suas estratégias comunicativas e ferramentas desenvolvidas, atentando para suas ações e como podem refletir na luta pelos direitos LGBT.

Conclui-se que a iniciativa ciberativista \#VoteLGBT colabora para a consolidação do movimento, na medida em que deu visibilidade para a existência de candidaturas comprometidas com a garantia dos direitos humanos de pessoas lésbicas, gays, bissexuais, travestis, transexuais e intersexos em todo o Brasil. Essas candidaturas são, por vezes, invisibilizadas dentro dos próprios partidos, que acabam se constituindo como os primeiros óbices aos projetos de transformação da realidade social e política.

A iniciativa \#VoteLGBT levou as questões pertinentes ao intento de mudança para a seara da política institucional, elegendo, para tanto, o caminho do Legislativo, por compreender que tão importante quanto a legitimidade (construída historicamente) das suas questões é a sua legalidade, ou seja, a garantia assegurada por meio de leis, seja em âmbito federal, estadual ou municipal. Assim, pode-se concluir que a iniciativa produziu uma tripla visibilização: das candidaturas para os eleitores, ao revelar a existência e pertinência delas; dos eleitores para os candidatos, ao demostrar que há sujeitos dispostos e com interesses específicos na defesa dos direitos LGBT; das demandas e temáticas para os candidatos e eleitores, ao expor reivindicações constituídas sobre as experiências históricas e contemporâneas de pessoas que compõem grupos sociais minorizados, assegurando, assim, a sensibilização da esfera pública a partir da inserção da agenda construída e defendida pelos diferentes atores que constituem o movimento LGBT no debate político. 
A campanha \#VoteLGBT oferece contribuições para o aprofundamento da democracia na medida em que expõe desigualdades políticas veladas pela própria noção de que, no regime democrático, os candidatos dispõem das mesmas possibilidades para disputarem o espaço da política institucional, ou seja, o espaço das decisões. A possibilidade de candidatura de pessoas pró-direitos LGBT (ou que se identificam como LGBT) já reflete um feito relevante, mas que não deve encerrar-se em si, porque a candidatura para a disputa política reflete que condições mínimas para tanto foram alcançadas. Ou seja, isso é significativo ao se considerar que, antes de poderem ocupar o espaço da disputa política, muitos candidatos precisam enfrentar o espaço da sobrevivência, enfrentar o contexto de vulnerabilidade social e política que os envolvem.

Além de lançar mão das possibilidades oferecidas pelos mecanismos de sites de redes sociais e de compartilhamento de conteúdo, os responsáveis pela iniciativa desenvolveram e disponibilizaram ferramentas sociais digitais que cumpriram a função de auxílio aos eleitores e candidatos através da aproximação de ambas as dimensões, civil e política, em uma mesma ambiência. Essas ferramentas, portanto, contribuíram para o escopo da campanha de fomentar a participação e a intervenção na política, com vistas a ampliar o número de representantes pró-direitos LGBT no cenário político brasileiro. Houve também o aperfeiçoamento das possibilidades técnicas de ferramentas digitais disponibilizadas para eleitores e candidatos, considerando que se migrou de um site mais estático, com característica curadora, para uma plataforma dinâmica, com característica responsiva.

\section{Referências}

1. Lopes JW, Veloso MSF. Explorando os estudos sobre o ciberativismo LGBT no Brasil: um movimento de pesquisa da pesquisa. In: Nobre IM, Costa SGA, Andrade AO, organizadores. A construção da pesquisa em estudos da mídia e práticas sociais. Campina Grande: EDUEPB; 2017; p. 90-108.

2. Simões JA, Facchini R. Na trilha do arco-íris: do movimento homossexual ao LGBT. São Paulo: Fundação Perseu Abramo; 2009.

3. Oliveira D. Movimentos sociais e uma nova cultura política em tempos de ação direta do capital. Aracê [Internet]. jun. 2014 [citado em 2016 set. 12];1(1):89-109. Disponível em: https://arace.emnuvens.com.br/ arace/article/view/9/9.

4. Santos GGC. Diversidade sexual e política eleitoral: analisando as candidaturas de travestis e transexuais no Brasil contemporâneo. Sex Salud Soc [Internet]. ago. 2016 [citado em 2016 out. 4];23:58-96. Disponível em: https://bit.ly/2xzp5ZN. doi: http://dx.doi.org/10.1590/1984-6487.sess.2016.23.03.a.

5. Lopes JW, Nunes PS, Veloso MSF. Ciberactivismo LGBT: un análisis de las publicaciones de la iniciativa \#VoteLGBT (Brasil). Disertaciones [Internet]. 2019 [citado en 2019 enero 20];12(1):112-27. Disponible: https://bit.ly/2Jk1t2a. doi: http://dx.doi.org/10.12804/revistas.urosario.edu.co/disertaciones/a.6984.

6. Wray S. Electronic civil disobedience and the world wide web of hacktivism: a mapping of extraparliamentarian direct action net politics. Switch [Internet]. 1998 [cited 2016 Dec 19];4(2). Available from: http://nknu.pbworks.com/f/netaktivizam.pdf.

7. Gibson W. Neuromancer. New York: Ace; 1984.

8. Rheingold H. Multitudes inteligentes: la próxima revolución social. Barcelona: Editorial Gedisa; 2004.

9. Malini F, Antoun H. A internet e a rua: ciberativismo e mobilização nas redes sociais. Porto Alegre: Sulina; 2013.

10. Silveira SA. Ciberativismo, cultura hacker e o individualismo colaborativo. Revista USP [Internet]. 2010 [citado em 2016 ago. 1];86:28-39. Disponível em: https://bit.ly/2fe25G2. doi: https://doi.org/10.11606/ issn.2316-9036.v0i86p28-39.

11. Langman L, Morris D. Internet mediation: a theory of alternative globalization movements. In: Proceedings of the International Workshop on Community Informatics; 2002 [dates unknown]. Montreal: [publisher unknown]; 2002. 
12. Vegh S. Classifying forms of online activism: the case of cyberprotests against the world bank. In: McCaughey M, Ayers MD, editors. Cyberactivism: online activism in theory and practice. New York: Routledge; 2003; p.71-96.

13. Denning DE. Activism, hacktivism, and cyberterrorism: the internet as a tool for influencing foreign policy. In: Arquilla J, Ronfeldt D, editors. Networks and netwars: the future of terror, crime, and militancy. Santa Monica: RAND Corporation; 2001. p. 239-88.

14. Rigitano MEC. Ciberativismo: definições, origens e possíveis classificações. In: Lemos A, organizador. Cibercidade II: Ciberurbe. A cidade na sociedade da informação. Rio de Janeiro: e-papers; 2005. p. 249-76.

15. Ugarte D. El poder de las redes: manual ilustrado para personas, colectivos y empresas abocados al ciberactivismo. Madrid: Edição do Autor; 2007.

16. Earl J, Kimport K, Prieto G, Rush C, Reynoso K. Changing the world one webpage at a time: conceptualizing and explaining internet activism. Mobilization [Internet]. 2010 Dec [cited 2016 Dec 19];15(4):425-46. Disponível em: https://bit.ly/2xCgshc. doi: https://doi.org/10.17813/ maiq.15.4.w03123213lh37042.

17. Di Felice M. Ser redes: o formismo digital dos movimentos net-ativistas. Matrizes [Internet]. 2013 [citado em 2016 jan. 3];7(2):49-71. Disponível em: https://bit.ly/32cog7z. doi: https://doi. org/10.11606/issn.1982-8160.v7i2p49-71.

18. Condorelli A. Da mobilização ciberativista a uma biopolítica das redes. II Congresso Internacional de Net-Ativismo; São Paulo [datas desconhecidas]. São Paulo: USP; 2015.

19. Di Corinto A, Tozzi T. Hacktivism: la libertà nelle maglie della rete. Roma: Manifestolibri; 2002.

20. Lopes JW. \#VoteLGBT: ciberativismo por representação política no Brasil [dissertação]. Natal: Universidade Federal do Rio Grande do Norte; 2018.

21. Valenzuela S. Unpacking the use of social media for protest behavior: the roles of information, opinion expression, and activism. Am Behav Sci [Internet]. 2013 Mar [cited 2016 Dec 19];57(7):920-42. Disponível em: https://bit.ly/2XBOG0G. doi: https://doi.org/10.1177/0002764213479375.

22. Castells M. Redes de indignación y esperanza. Madrid: Alianza Editorial; 2012.

23. Han BC. En el enjambre. Barcelona: Heder; 2014.

24. Pariser E. O filtro invisível: o que a internet está escondendo de você. Rio de Janeiro: Zahar; 2012.

25. Scolari C. Hipermediaciones: elementos para una teoría de la comunicación digital interactiva. Barcelona: Editorial Gedisa; 2008.

26. Tilly C, Wood LJ. Los movimientos sociales, 1768-2008: desde sus orígenes a Facebook. Crítica: Barcelona; 2010.

27. Yin RK. Estudo de caso: planejamento e métodos. 2. ed. Porto Alegre: Bookman; 2001.

28. Recuero R. Contribuições da análise de redes sociais para o estudo das redes sociais na Internet: o caso da hashtag \#Tamojuntodilma e \#CalaabocaDilma. Fronteira [Internet]. 2014 ago. [citado em 2017 out. 17];16(2):60-77. Disponível em: https://bit.ly/2QzL9eE. doi: http://dx.doi.org/10.4013/fem.2014.162.01.

29. Bardin L. Análise de conteúdo. Lisboa: Edições 70; 1977.

30. Green JN. A luta pela igualdade: desejos, homossexualidade e a esquerda na América Latina. Cadernos AEL [Internet]. 2003 [citado em 2017 fev. 15];10(18/19):13-43. Disponível em: https://bit.ly/2LHIGjR.

31. Santos GGC. Movimento LGBT e partidos políticos no Brasil. Contemporânea [Internet]. jun. 2016 [citado em 2016 out. 4];6(1):179-212. Disponível em: https://bit.ly/2XykW35. doi: http://dx.doi. org/10.4322/2316-1329.005.

32. Pitkin HF. El concepto de representación. Madrid: Centro de Estudios Constitucionales; 1985.

33. Sartori G. Elementos de teoría política. Madrid: Alianza Editorial; 1992. 